\title{
Development of an Analytical Line Source Dispersion Model to Predict Ground Level Concentrations for Particulate Matter (PM) of Different Particle Size Ranges ${ }^{\dagger}$
}

\author{
Saisantosh Vamshi Harsha Madiraju (D) and Ashok Kumar*
}

The College of Engineering, The University of Toledo, Toledo, OH 43606, USA; smadira@rockets.utoledo.edu

* Correspondence: ashok.kumar@utoledo.edu; Tel.: +1-419-530-8136

+ Presented at the 4th International Electronic Conference on Atmospheric Sciences, 16-31 July 2021; Available online: https:/ / ecas2021.sciforum.net.

Citation: Madiraju, S.V.H.; Kumar, A Development of an Analytical Line Source Dispersion Model to Predict Ground Level Concentrations for Particulate Matter (PM) of Different Particle Size Ranges. Environ. Sci. Proc. 2021, 8, 13. https://doi.org/ 10.3390/ecas2021-10355

Academic Editor: Anthony R. Lupo

Published: 22 June 2021

Publisher's Note: MDPI stays neutral with regard to jurisdictional claims in published maps and institutional affiliations.

Copyright: (c) 2021 by the authors. Licensee MDPI, Basel, Switzerland. This article is an open access article distributed under the terms and conditions of the Creative Commons Attribution (CC BY) license (https:// creativecommons.org/licenses/by/ $4.0 /)$.

\begin{abstract}
Particulate matter (PM) is released in varying quantities from mobile sources depending on the type of fossil fuel used in combustion. According to the USEPA, PM exposure could cause a variety of problems such as premature deaths, nonfatal heart attacks, irregular heartbeat, asthma, reduced lung function, and respiratory issues. Therefore, it is necessary to predict the downwind concentrations near highways from mobile sources to protect the public from adverse health effects. The current study concentrates on developing an analytical line source dispersion model to account for different particle size ranges for particulate matter released from mobile sources. Available line source models do not explicitly consider different ranges of particle sizes present in the exhaust. The present study discusses the development of a dispersion model to predict downwind concentrations of PM by incorporating a range of particle sizes for an infinite and a finite-length mobile source. The dry deposition of particles is also considered during development. The emission rate, wind speed, wind direction, atmospheric turbulence, and dry deposition velocity of the particles are the model inputs. The sensitivity of the model is determined by simultaneously varying the independent input variables using Monte Carlo simulation by Crystal Ball software. The sensitivity analysis results generated using Crystal Ball are preliminary in nature and should be re-examined.
\end{abstract}

Keywords: line source model; dispersion; particulate matter; particle size; dry deposition; sensitivity analysis; Crystal Ball software

\section{Introduction}

In the US, cars and other motorized vehicles have been the source of about half of the total air pollution [1]. This pollution originates from both direct tailpipe emissions and the mechanical wear of different parts of the vehicle. The major emissions from automobiles include carbon monoxide, hydrocarbons, nitrogen oxides, lead, and particulate matter [2]. The concentration of these emissions should be estimated for the implementation of federal and local regulations [3].

Particulate matter (PM) is made up of tiny particles of solids/liquids that are in the air. These particles may include dust, dirt, soot, smoke, and drops of liquid. They could affect human health irrespective of their size [4]. Breathing in particle pollution can be harmful to health. Dust from roads, farms, dry riverbeds, construction sites, and mines is composed of particulate matter of less than $10 \mu \mathrm{m}\left(\mathrm{PM}_{10}\right)$ [5].

Many models are available in the literature to predict the concentrations of contaminants at downwind distances from different sources. Most of these models are aerosol dynamics models that use methods that are based on particle size. Each model has its criteria for the particle size that it is used for. UHMA (the University of Helsinki Multicomponent Aerosol Model) is a dispersion model developed at the University of Helsinki with a focus on the growth and development of new particles. The model is evaluated in 
the studies conducted by Pitjola et al. and Korhonen et al. [6,7]. MONO32 is a model containing four size modes, which follows a monodisperse approach, particularly for particle sizes between 7 and $450 \mathrm{~nm}$. This model was examined and evaluated by Pohjola et al. within $25 \mathrm{~s}$ following emission [8]. AERO is a dispersion model developed for particle sizes between 0.01 and $10 \mu \mathrm{m}$, with eight size distribution sections, and composition is assumed to be uniform in this model [9]. GATOR (the Gas Aerosol Transport Radiation Model) is an Eulerian dispersion model used for moving size or stationary size particles in urban and mesoscale environments [10]. MADRID (the Model of Aerosol Dynamics, Reaction, ionization, and Dissolution) was developed for particles of multiple sizes [11]. AEROFOR2 is a sectional box model that considers 200 evenly distributed sections in its particle size calculation method, and also considers externally or internally mixed variations that are distributed logarithmically within each size group. URM is an Eulerian dispersion model containing four groups that are under $10 \mu \mathrm{m}$ in size. The RPM model is considered for particle sizes between 0.01 and $0.07 \mu \mathrm{m}$. The CIT model, developed by the California Institute of Technology, is used for particle sizes of between 0.5 and $10 \mu \mathrm{m}$. All of the models discussed consider the effect of condensation/evaporation. The phenomenon of coagulation is considered by all the above-mentioned models except for URM and CIT in the simulation of predictions. The effect of dry deposition is incorporated in all the discussed models. However, the effect of wet deposition is considered only by AEROFOR, URM, and RPM [12].

The literature shows that the reported models, used for the estimation of concentrations, are not designed for releases from mobile sources. This study develops the SLINE PM 1.0 model, which could be used to calculate the ground-level concentrations of the PM, taking into account different particle size ranges. The model is developed for infinite and finite-length sources.

\section{Model Development}

The basic approach to developing the SLINE PM 1.0 model is based on the analytical solution of the convective-diffusion equation for a velocity field represented by a power law. This allows us to incorporate the variation of the wind velocity magnitude near the ground during the dispersion of PM released from mobile sources. The concentration Equation (1) given by Ermak [13], and used by Nimmatoori and Kumar [14] for a point at $(x, y, z)$ from an elevated source, is used for the development of SLINE PM 1.0.

$$
\begin{aligned}
& C_{(x, y, z)}=\frac{q}{2 \pi \sigma_{y} \sigma_{z} u} \exp \left\{\frac{-y^{2}}{2 \sigma_{y}^{2}}\right\} \exp \left\{\frac{-V_{g}(z-h)}{2 K}-\frac{V_{g}^{2} \sigma_{z}^{2}}{8 K^{2}}\right\} \\
{\left[\exp \left\{\frac{-(z-h)^{2}}{2 \sigma_{z}^{2}}\right\}+\right.} & \left.\exp \left\{\frac{-(z+h)^{2}}{2 \sigma_{z}^{2}}\right\}-\sqrt{2 \pi} \frac{V_{1} \sigma_{z}}{K} \exp \left\{\frac{V_{1}(z+h)}{K}+\frac{V_{1}^{2} \sigma_{z}^{2}}{2 K^{2}}\right\} \operatorname{erfc}\left\{\frac{V_{1} \sigma_{z}}{\sqrt{2} K}+\frac{z+h}{\sqrt{2} \sigma_{z}}\right\}\right] \\
\text { where: } & \\
& \left.C_{(x, y, z)}=\text { concentration (units } / \mathrm{m}^{3}\right) ; \\
q & =\text { emission rate (units/s); } \\
u & =\text { wind speed (m/s); } \\
& \sigma_{y}=\text { horizontal dispersion coefficient }(\mathrm{m}) ; \\
& \sigma_{z}=\text { vertical dispersion coefficient }(\mathrm{m}) ; \\
z & =\text { the height measured from the surface of the ground }(\mathrm{m}) ; \\
& h=\text { height of the source; } \\
& V_{1}=\left(V_{d}-V_{g}\right) / 2 ; \\
& V_{d}=\text { dry deposition velocity of the particle (m/s); } \\
& V_{g}=\text { gravitational settling velocity of the particle }(\mathrm{m} / \mathrm{s}) ; \\
& \left.K=\text { eddy diffusivity (m } \mathrm{m}^{2} / \mathrm{s}\right) .
\end{aligned}
$$

The profiles of wind velocity and eddy diffusivity at a given downwind distance are given by $u=u_{1}\left(\frac{z}{z_{1}}\right)^{m}$ and $K=K_{1}\left(\frac{z}{z_{1}}\right)^{n}$, respectively. 
The downwind concentrations from a line source are obtained by integrating Equation (1) for a point source. There are two choices that can be made while carrying out the integration depending on the choice of length of the line source.

The finite length $(\mathrm{Y})$ equation given by Nimmatoori and Kumar [14] is adopted for the calculation of downwind concentrations. They obtained Equation (2) by integrating Equation (1) from $-\mathrm{Y} / 2$ to $\mathrm{Y} / 2$.

$$
\begin{gathered}
C_{(x, y, z)}=\frac{q}{2 \sqrt{2 \pi} \sigma_{z} u} \exp \left\{\frac{-V_{g}(z-h)}{2 K}-\frac{V_{g}^{2} \sigma_{z}^{2}}{8 K^{2}}\right\} \\
{\left[\exp \left\{\frac{-(z-h)^{2}}{2 \sigma_{z}^{2}}\right\}+\exp \left\{\frac{-(z+h)^{2}}{2 \sigma_{z}^{2}}\right\}-\sqrt{2 \pi} \frac{V_{1} \sigma_{z}}{K} \exp \left\{\frac{V_{1}(z+h)}{K}+\frac{V_{1}^{2} \sigma_{z}^{2}}{2 K^{2}}\right\} \operatorname{erfc}\left\{\frac{V_{1} \sigma_{z}}{\sqrt{2} K}+\frac{z+h}{\sqrt{2} \sigma_{z}}\right\}\right]\left[\operatorname{erf}\left(\frac{\frac{\gamma}{2}}{\sqrt{2} \sigma_{y}}\right)-\operatorname{erf}\left(\frac{-\frac{\gamma}{2}}{\sqrt{2} \sigma_{y}}\right)\right]}
\end{gathered}
$$

An infinite length source equation was derived from Equation (1) and is given as Equation (3) for the computation of ground-level concentrations.

$$
\begin{gathered}
C_{(x, y, z)}=\frac{q}{\sqrt{2 \pi} \sigma_{z} u} \exp \left\{\frac{-V_{g}(z-h)}{2 K}-\frac{V_{g}^{2} \sigma_{z}^{2}}{8 K^{2}}\right\} \\
{\left[\exp \left\{\frac{-(z-h)^{2}}{2 \sigma_{z}^{2}}\right\}+\exp \left\{\frac{-(z+h)^{2}}{2 \sigma_{z}^{2}}\right\}-\sqrt{2 \pi} \frac{V_{1} \sigma_{z}}{K} \exp \left\{\frac{V_{1}(z+h)}{K}+\frac{V_{1}^{2} \sigma_{z}^{2}}{2 K^{2}}\right\} \operatorname{erfc}\left\{\frac{V_{1} \sigma_{z}}{\sqrt{2} K}+\frac{z+h}{\sqrt{2} \sigma_{z}}\right\}\right]}
\end{gathered}
$$

The expressions for the horizontal and vertical dispersion coefficients for stable conditions are given as Equations (4) and (5), and the expressions for unstable conditions are given as Equations (6) and (7). These equations are based on the work of Snyder et al. [15] and include an additional term $m_{t}$ to account for the additional vertical spread caused by the vehicular turbulence, as suggested by Madiraju and Kumar [16].

$$
\begin{gathered}
\sigma_{z}=a \frac{u_{*}}{U_{e}} x \frac{1}{\left(1+b_{s} \frac{u_{*}}{u_{e}}\left(\frac{x}{L}\right)^{\frac{2}{3}}\right)}+m_{t} \\
\sigma_{y}=c \frac{\sigma_{v}}{u_{*}} \sigma_{z}\left(1+d_{s} \frac{\sigma_{z}}{|L|}\right) \\
\sigma_{z}=\mathrm{a} \frac{u_{*}}{U_{e}} x\left(1+b_{u} \frac{x u_{*}}{L U_{e}}\right)+m_{t} \\
\sigma_{y}=c \frac{\sigma_{v}}{u_{*}} \sigma_{z}\left(1+d_{u} \frac{\sigma_{z}}{|L|}\right)^{-\frac{1}{2}}
\end{gathered}
$$

where $u_{*}$ is the surface friction velocity, $U_{e}$ is the effective wind speed, $L$ is the MoninObukhov length, $m_{t}$ is vertical spread due to the turbulence created by the vehicles.

$m_{t}$ is computed using the formulation given by Madiraju and Kumar [16]: $m_{t}=$ $(1.7 \mathrm{H}) / 2.15$, where $\mathrm{H}$ is the height of the vehicle.

The values of the parameters: a, c, $b_{s}, d_{s} b_{u}$, and $d_{u}$ are also taken from Snyder et al. [15]. These coefficients depend on the atmospheric stability conditions.

Note that $K$ is assumed to be constant with downwind distance ' $x$ ' in Equation (3) during its derivation. The value of $K$ is determined by Equation (8), based on the work of Rao [17], and Nimmatoori and Kumar [14].

$$
\mathrm{K}=\frac{\sigma_{Z}^{2} u_{1}}{2 x}
$$

The use of Equation (8) at different downwind distances indicates that $\mathrm{K}$ is a function of $x$. It is assumed that the model will perform better if the value of $\mathrm{K}$ is updated at each downwind distance. 
The dry deposition velocity $\left(V_{d}\right)$ and gravitational settling velocity $\left(V_{g}\right)$ of the particles are computed using the algorithms used in AERMOD by USEPA [18]. The expressions are given as Equations (9) and (10)

$$
V_{d}=\frac{1}{R_{a}+R_{p}+R_{a} R_{p} V_{g}}+V_{g}
$$

where:

$R_{a}=$ Aerodynamic resistance $(\mathrm{s} / \mathrm{m}) ;$

$R_{p}=$ Quasi-laminar sublayer resistance.

$$
V_{g}=\frac{\left(\rho-\rho_{a i r}\right) g d_{p}^{2} C_{2}}{18 \mu} S_{C F}
$$

where:

$\rho=$ particle density $\left(\mathrm{g} / \mathrm{cm}^{3}\right)$;

$\rho_{\text {air }}=$ air density $\left(\mathrm{g} / \mathrm{cm}^{3}\right)$;

$d_{p}=$ particle diameter $(\mu \mathrm{m}) ;$

$g=$ acceleration due to gravity $\left(\mathrm{m} / \mathrm{s}^{2}\right) ;$

$\mu=$ absolute viscosity of air $(\mathrm{g} / \mathrm{cm} / \mathrm{s})$;

$C_{2}=$ air unit's conversion constant $\left(\mathrm{cm}^{2} / \mu \mathrm{m}^{2}\right)$;

$S_{C F}=$ slip correction factor (dimensionless).

\section{Application of the Model}

The developed model is applied as follows depending on the availability of the particle size profile of the emitted PM.

1. Emission data with given particle size profile: if the input data available to run the simulation to predict the ground-level concentration of the PM include the detailed distributions of the particle sizes, then the formulation provided in Equations (2) and (3) is first applied to each range of particle size distribution. The total particulate concentration $\left(C_{T P}\right)$ will be the sum of concentrations for each size range.

2. Emission data with no particle size distribution: if the input data available to run the simulation to predict the ground-level concentration of the PM does not include the detailed distributions of the particle sizes, then the formulation provided in Equations (2) and (3) is used.

\section{Model Results}

A test case was developed using data collected from the literature to perform the simulations. The source information, meteorological data, and the surrounding terrain input data were based on the findings of Snyder et al. [15,19] and Nimmatoori and Kumar [14,20]. The atmospheric stability input parameters such as Monin-Obukhov length (L), friction velocity $\left(u_{*}\right)$, and convective velocity $\left(w_{*}\right)$ were derived from the field data used by Snyder et al. They were needed to compute the $R_{a}$ and $R_{p}$ in Equation (9). All the other input parameters were based on the AERMOD User's Guide by USEPA $[18,21]$.

The model results were generated for the SLINE PM 1.0 model using Equation (2) for the finite length source of $1 \mathrm{~km}$ and Equation (3) for an infinite length source. These results are compared, in Figure 1, with the concentrations calculated using a simple line source model (SLSM) given in the textbook by Wark et al. [22]. 


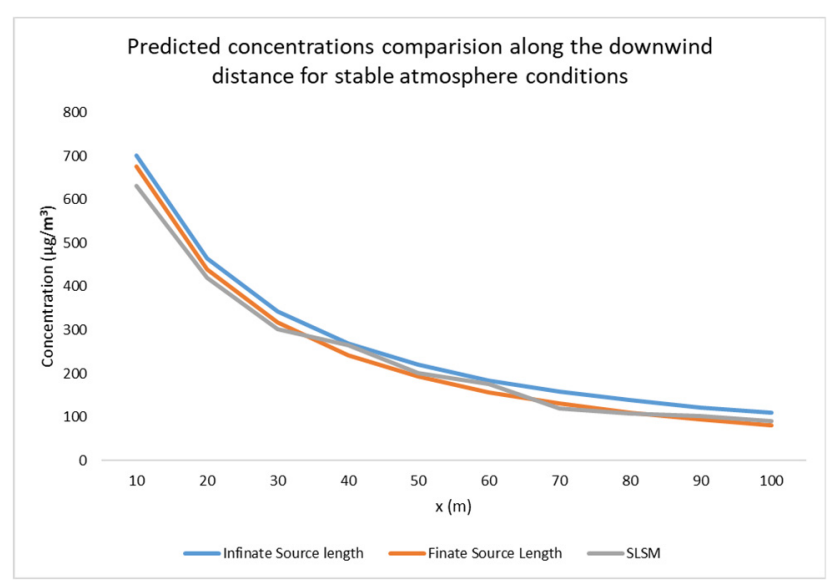

(a) Model results comparison for stable conditions

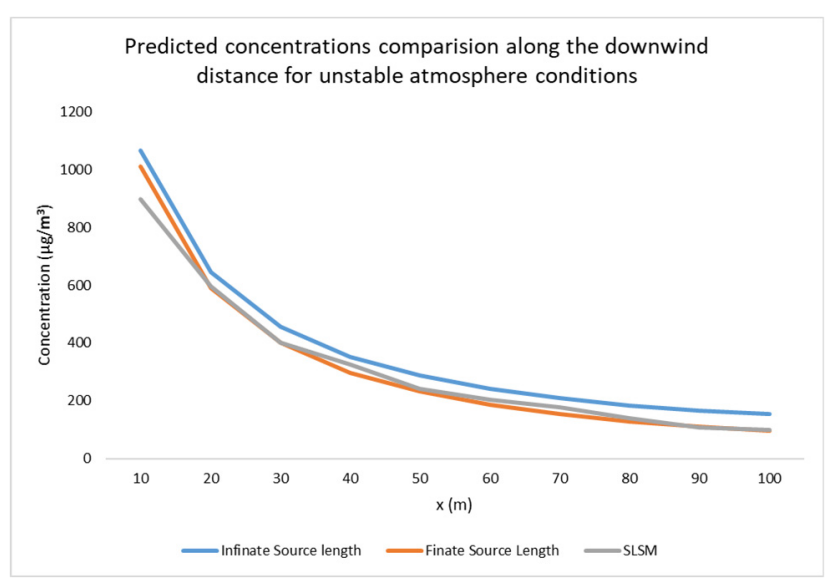

(b) Model results comparison for unstable conditions

Figure 1. Comparison of simulated concentrations using finite, infinite, and SLSM models.

The particle size in exhaust gases varies from 0.23 to $10 \mu \mathrm{m}$. The concentrations in Figure 1 represent the total particulate concentration (summation of all the PM sizes). Figure 1a represents the test case results under stable atmosphere conditions and Figure $1 \mathrm{~b}$ represents the test case results for the unstable atmospheric conditions. The concentrations for different downwind distances of up to $100 \mathrm{~m}$ from the source are shown.

As expected, the concentration of the pollutants decreases with the incremental downwind distance. However, it was observed from the computed concentrations for the infinite length source model are more than the concentrations of the PM predicted by the finite length source model. The finite length source model results are closer to the values of the SLSM model. Future model evaluations with the field data will clarify the choice of model.

\section{Sensitivity}

The sensitivity analysis of a dispersion model is the quantification of uncertainty in the model output concentrations based on its input variables/parameters. Currently, many tools are available to perform sensitivity analysis. In this study, the sensitivity analysis was performed on SLINE PM 1.0 using the Crystal Ball Software (version 11.1.2.4) [23]. The software allows the study of sensitivity by simultaneously varying all the input variables. Two test cases were considered in this study to assess the sensitivity of the input parameters/variables for the SLINE PM 1.0 representing each atmospheric stability. The selected input variables/parameters required for running SLINE PM 1.0 include the emission rate of the pollutant (q), the wind velocity at reference height $\left(u_{1}\right)$, the coefficient $a$, the coefficient $b_{s}$ (only for stable conditions), the coefficient $b_{u}$ (only for unstable conditions), and the surface friction velocity $u_{*}$. The maximum and minimum values for these variables were chosen based on the different distributions (e.g., normal distribution and lognormal distribution) used for each input. The distributions were selected based on the preliminary studies conducted in the literature.

The simulations were executed for each input variable/parameter in the pre-defined ranges by running 100,000 trials. The distributions of the variables in the considered range, for both stable and unstable conditions, are represented in Figures 2 and 3. The concertation simulations were also computed for 100,000 trials to identify the sensitivity that the SLINE PM 1.0 model shows towards the considered input variables/parameters. 


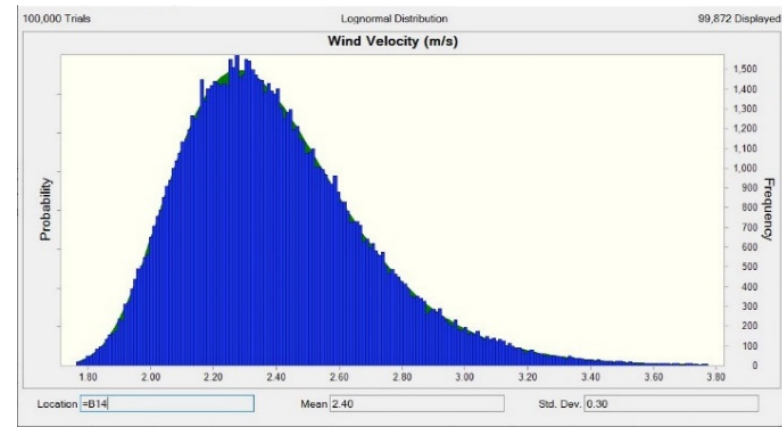

(a) Wind velocity input distribution range.

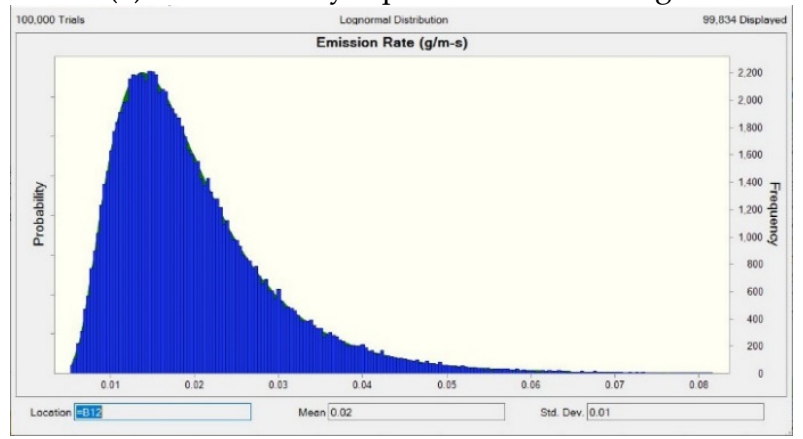

(c) Emission rate input distribution range.

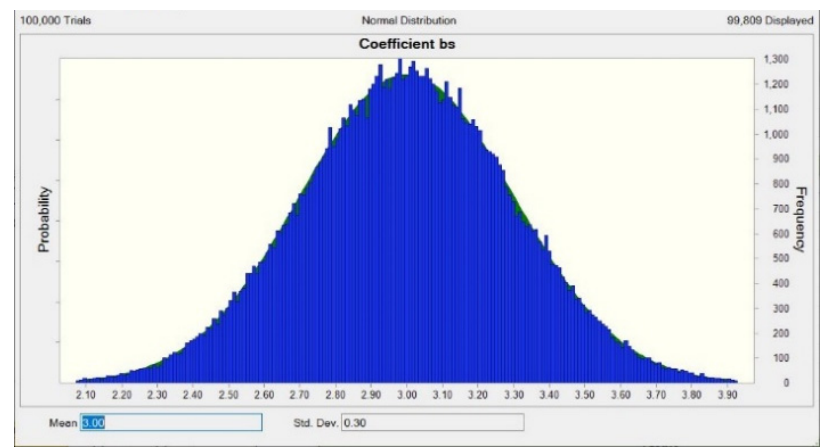

(e) Coefficient $m$ input distribution range.

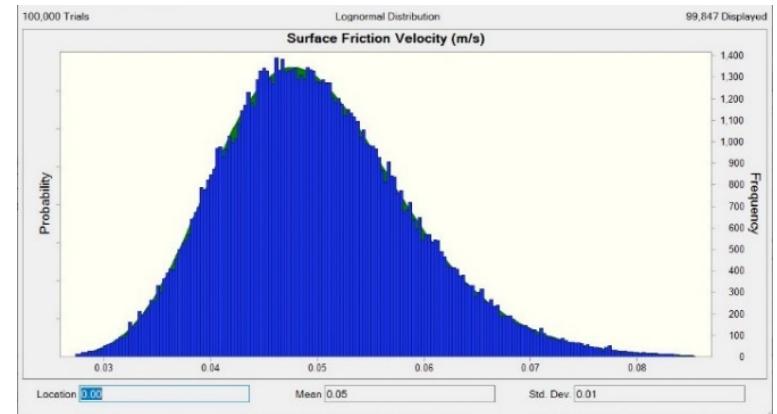

(b) Surface friction input distribution range.

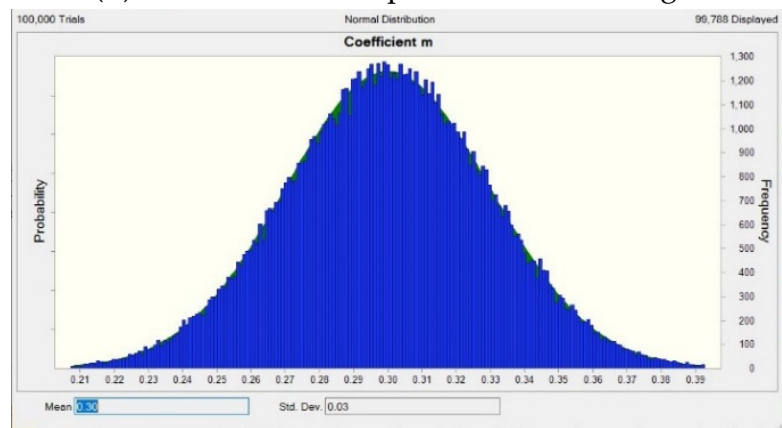

(d) Coefficient $\mathrm{m}$ input distribution range.

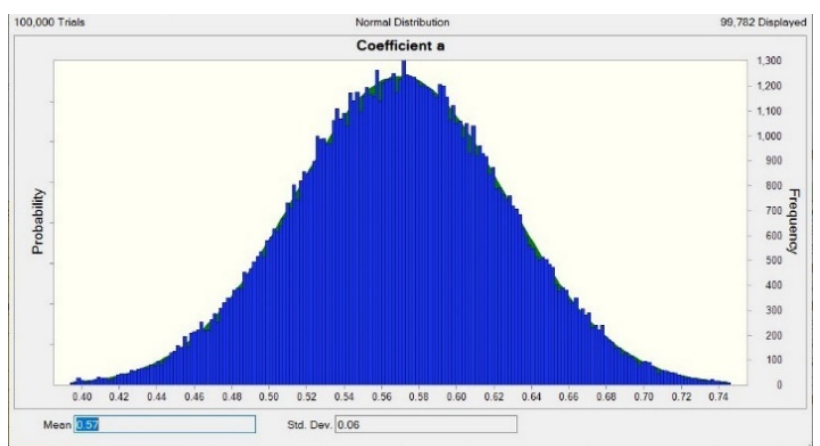

(f) Coefficient $a$ input distribution range.

Figure 2. The independent input variables' distribution rage considered for the sensitivity analysis for stable conditions.

The sensitivity results were computed using the Crystal Ball software (version 11.1.2.4) and are shown in Figure 4. The results are displayed in terms of the rank correlation coefficient. The rank correlation is always in the interval $[-1,1]$ and is invariant under any monotonic increasing transformation of the data. In the current sensitivity analysis, the rank correlation is used to assess the level of significance of the relation between the input variable/parameters and the predicted concentration. The " $-/+$ " signs denote the negative or positive correlation and the value represents the significance of the correlation [24]. 


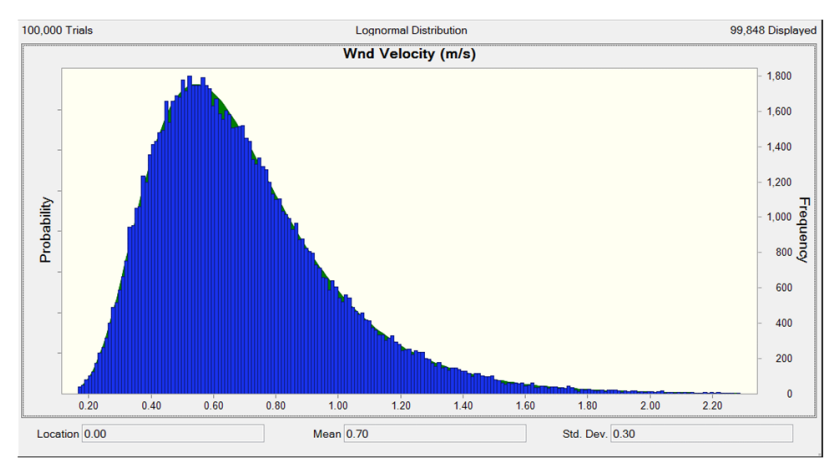

(a) Wind velocity input distribution range.

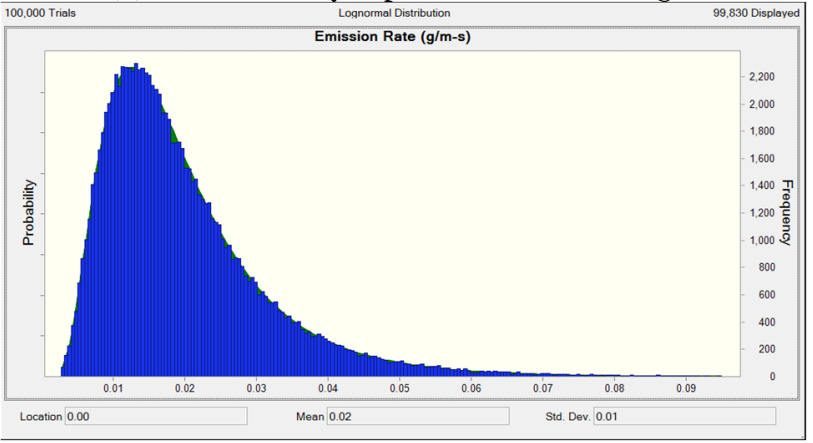

(c) Emission rate input distribution range.

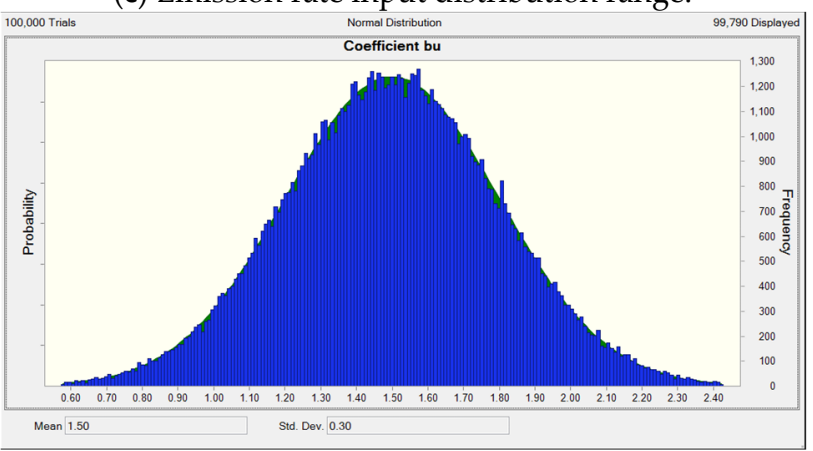

(e) Coefficient $m$ input distribution range.

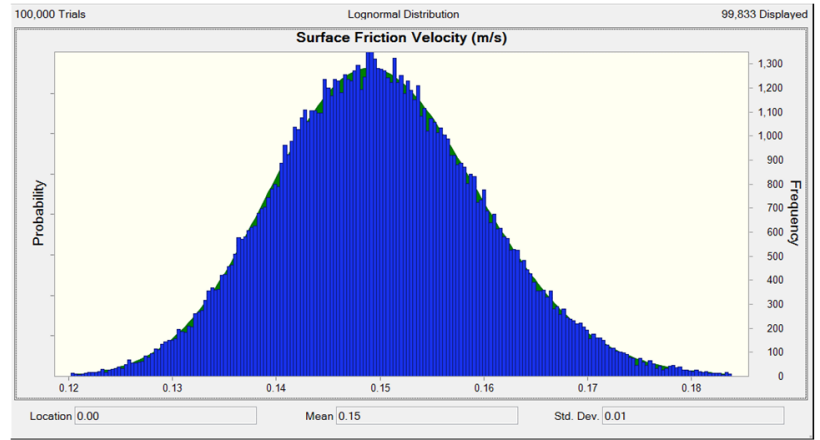

(b) Surface friction input distribution range.

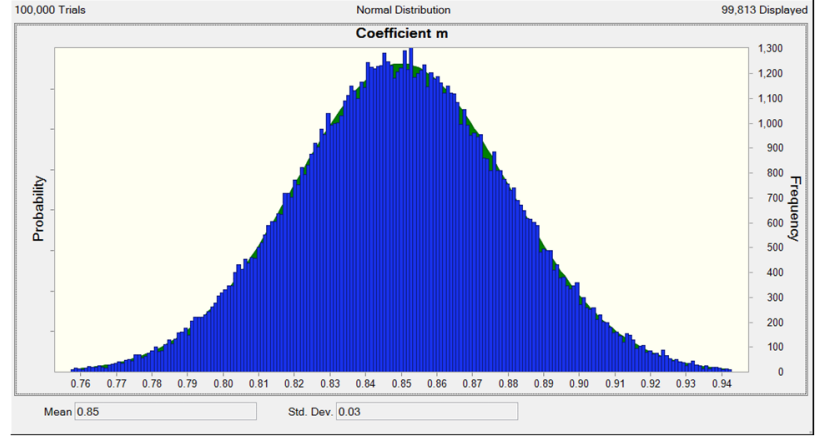

(d) Coefficient $\mathrm{m}$ input distribution range.

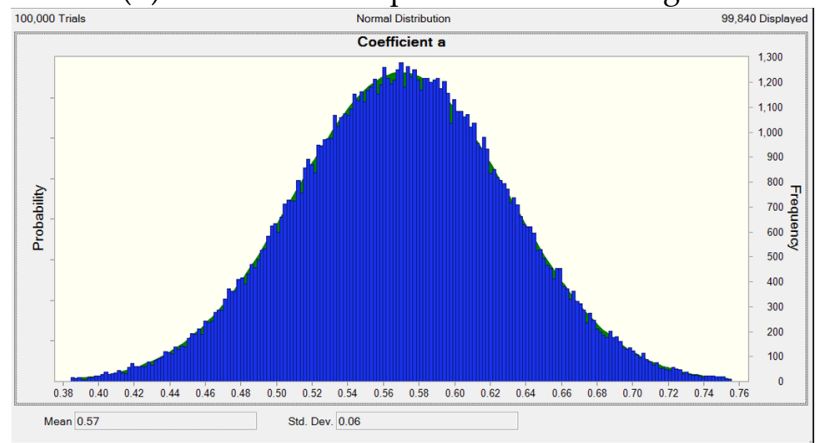

(f) Coefficient $a$ input distribution range.

Figure 3. The independent input variables distribution rage considered for the sensitivity analysis for unstable conditions.

Figure 5a,b indicate that the sensitivity values required to compute downwind concentrations are very similar for all the variables considered under stable conditions. These results show that the SLINE PM 1.0 model is most sensitive to the coefficient $m$, followed by the reference wind velocity $\left(u_{1}\right)$. The model is moderately sensitive to the emission rate $(q)$ and surface friction velocity $\left(u_{*}\right)$, and is almost insensitive to the coefficient $a$ and coefficient $b_{s}$. Thus, the concentrations predicted by SLINE PM1.0 are sensitive to the wind velocity and emission rate. One would expect this result for a typical dispersion model. 


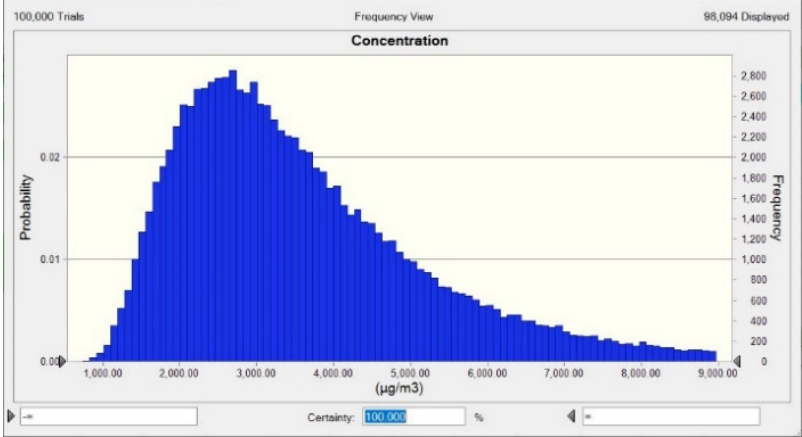

(a) Infinite-stable condition.

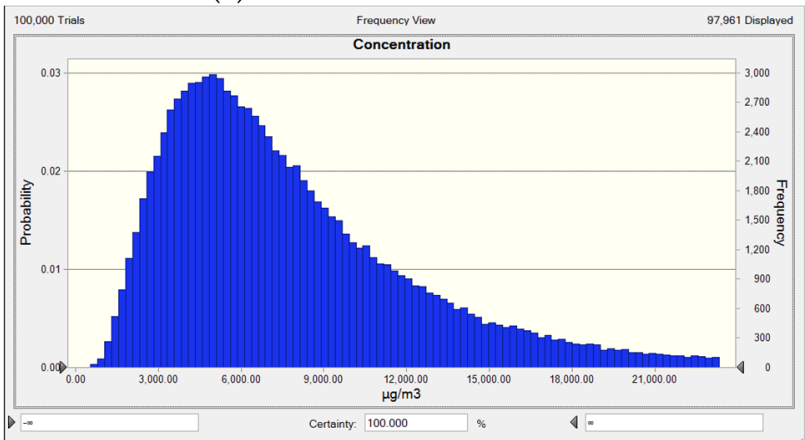

(c) Infinite-unstable condition.

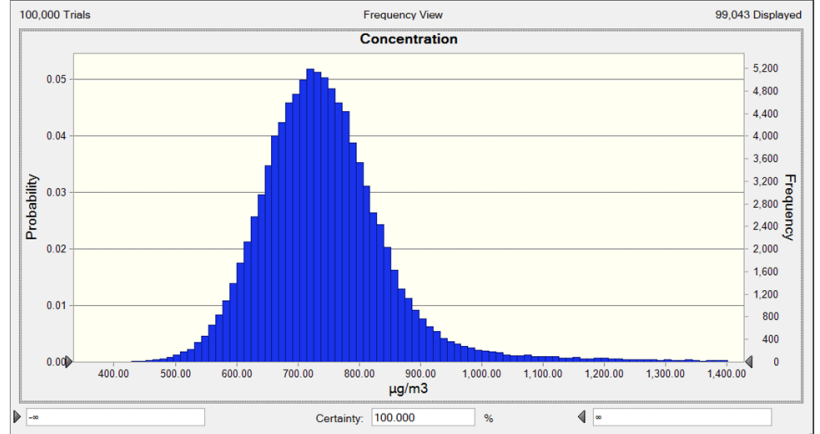

(b) Finite-stable condition.

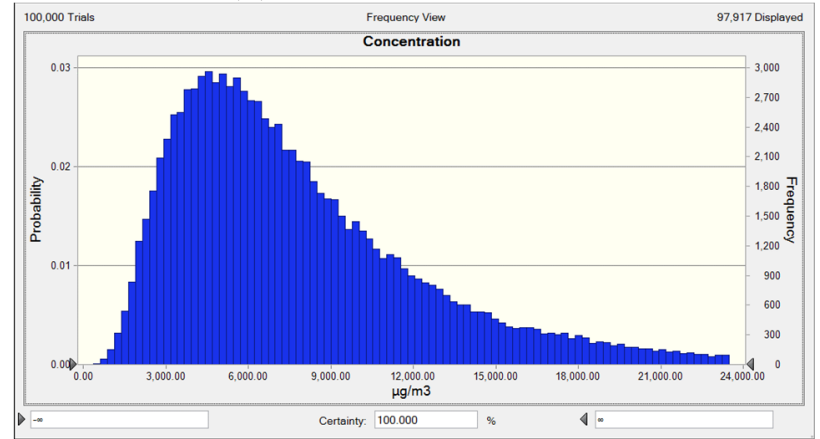

(d) Finite-unstable condition.

Figure 4. The simulated concentration distribution for infinite and finite-length sources, respectively, for stable atmospheric conditions.

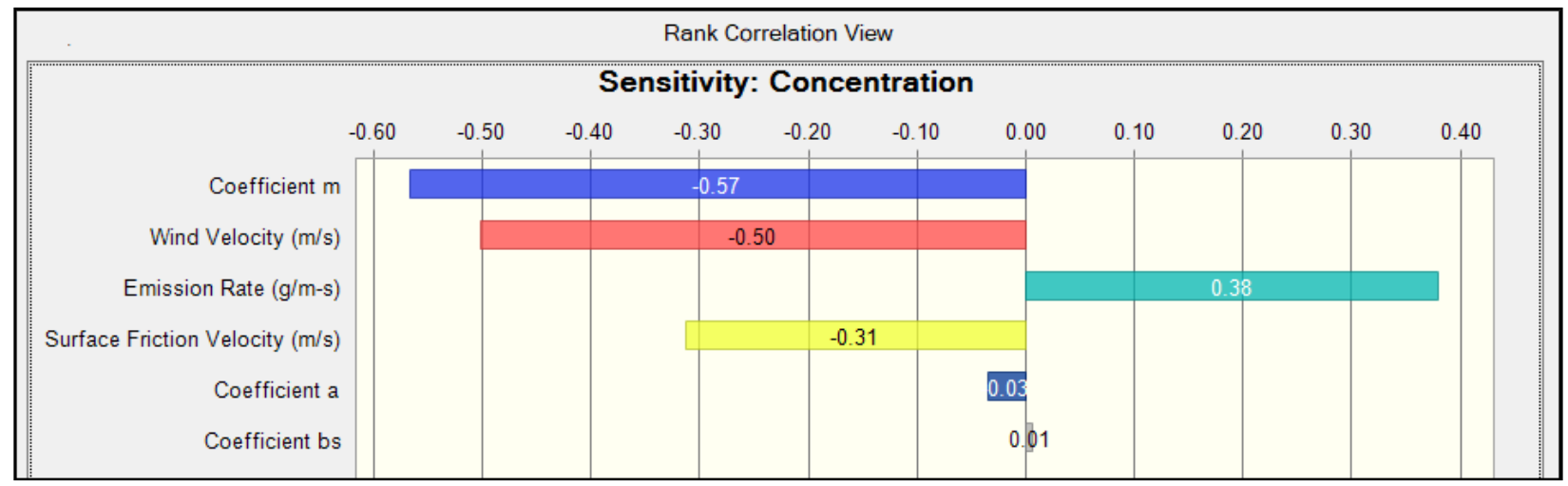

(a) Sensitivity analysis results for the infinite length source for stable conditions.

Figure 5. Cont. 


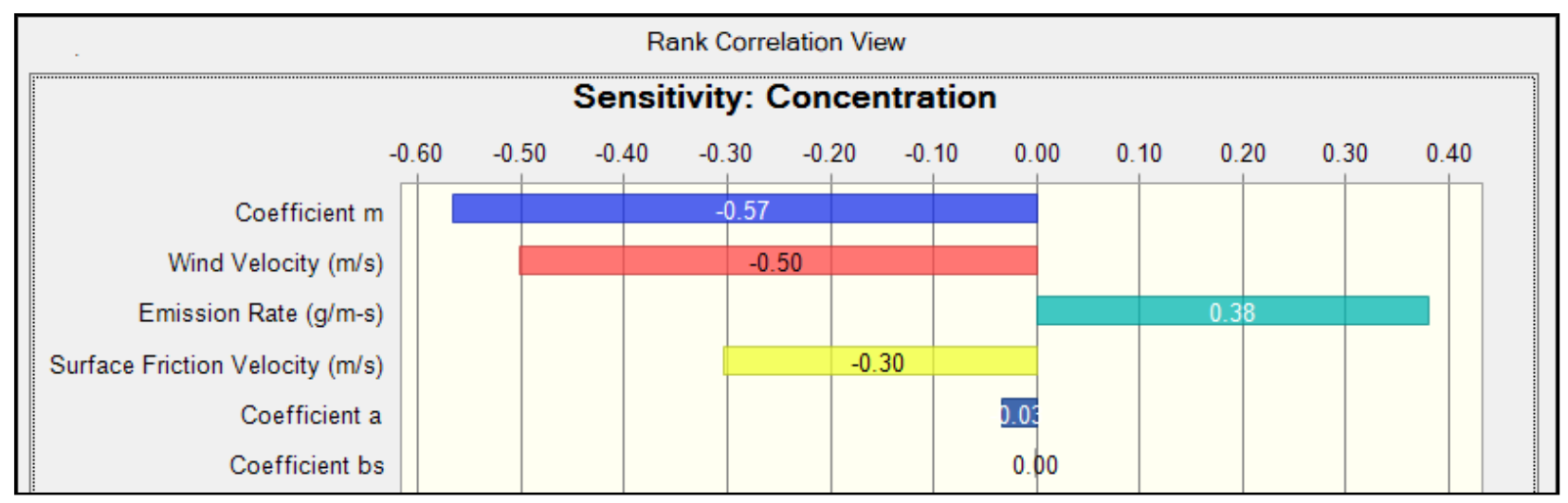

(b) Sensitivity analysis results for the finite length source for stable conditions.

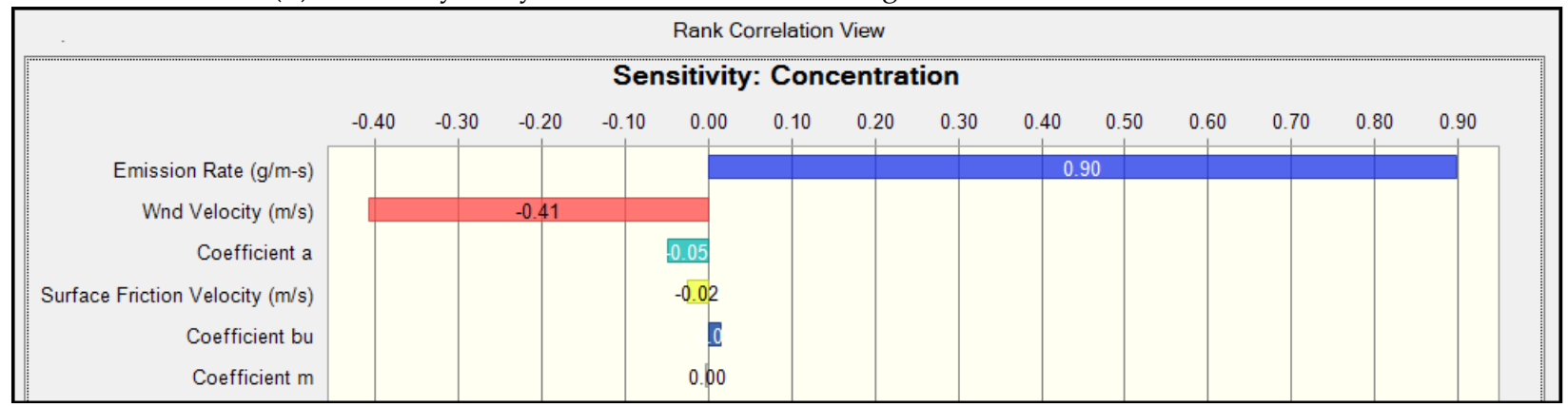

(c) Sensitivity analysis results for the infinite length source for unstable conditions.

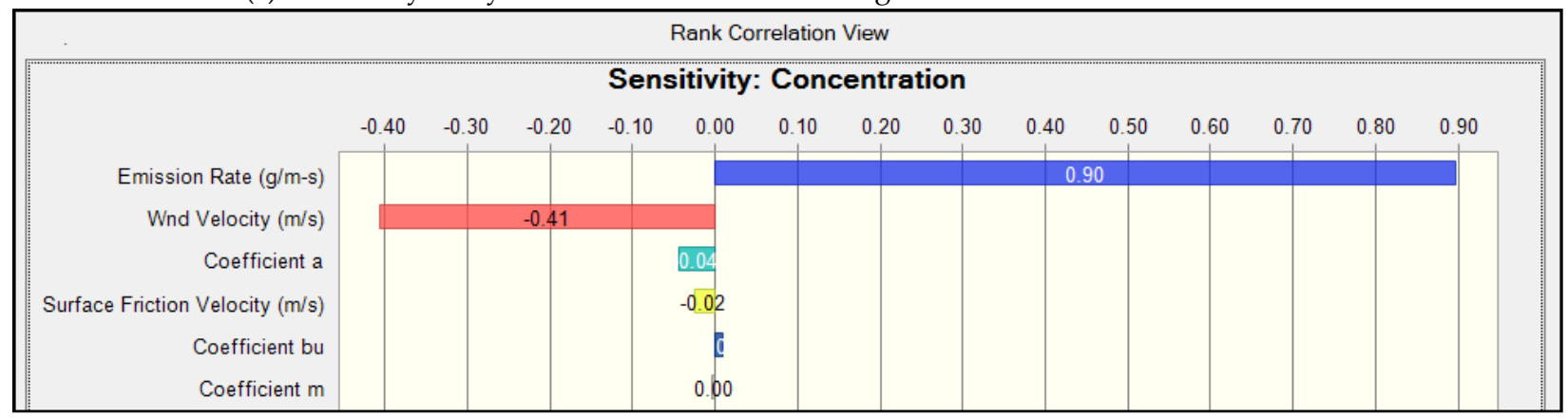

(d) Sensitivity analysis results for the finite length source for unstable conditions.

Figure 5. The sensitivity analysis results using Crystal Ball (version 11.1.2.4).

Figure $5 \mathrm{c}$, d show that the sensitivity values needed to compute the downwind groundlevel concentrations are similar for all the variables under unstable conditions. The model is most sensitive to the emission rate $(q)$, followed by reference wind velocity $\left(u_{1}\right)$ for both infinite and finite-length sources. This model is slightly sensitive to the coefficient $a$ and surface friction velocity $\left(u_{*}\right)$ and almost insensitive to the coefficient $b_{u}$ and coefficient $m$.

Overall, the sensitivity analysis determines the effect of the variation of the input parameters on final concentrations obtained using the SLINE PM 1.0 model. In general, the analysis shows that emission rate $(q)$ is positively correlated and velocity is negatively correlated. The surprising result is that the variables related to dispersion coefficients show very little sensitivity. This result is different than the one reported by Harsha and Kumar [16,25-27] using the ASTM method and the Sensitivity-Index method. The analysis performed using Crystal Ball should be re-examined. Therefore the sensitivity results are preliminary in nature.

\section{Conclusions}

Overall, this study presents the development of SLINE PM 1.0, an analytical line source dispersion model used to predict the ground-level concentrations for PM in different particle size ranges. Separate dispersion equations are presented for the infinite and finite- 
length sources. The total concentrations computed using the developed equations were compared with a simple line source model SLSM available in the textbook.

The model sensitivity is determined using the Crystal Ball software (version 11.1.2.4). The rank correlation coefficient is used to identify the sensitivity of the SLINE PM 1.0 model to the input variables: the emission rate of the pollutant $(q)$, the wind velocity at the reference height $\left(u_{1}\right)$, the coefficient $a$, the coefficient $b_{s}$ (only for stable conditions), the coefficient $b_{u}$ (only for unstable conditions), the surface friction velocity $u_{*}$, and the exponent of the power-law profile. The sensitivity analysis results indicate that the SLINE PM 1.0 model is highly sensitive to the emission rate and wind velocity. The sensitivity results for this model are preliminary and need to be re-examined. The model should be evaluated using the data from field studies.

Author Contributions: Conceptualization, A.K., and S.V.H.M.; Investigation, A.K., and S.V.H.M.; Methodology, A.K., and S.V.H.M.; Project administration, A.K.; Supervision, A.K.; Validation, A.K.; Writing-Original draft, S.V.H.M.; Writing-Review and editing, A.K. All authors have read and agreed to the published version of the manuscript.

Funding: This research received no external funding.

Acknowledgments: The authors would like to thank The University of Toledo for providing the facilities to support this research.

Conflicts of Interest: The authors declare no conflict of interest.

\section{References}

1. US EPA. History of Reducing Air Pollution from Transportation in the United States. USEPA. 10 September 2015. Available online: https: / / www.epa.gov / transportation-air-pollution-and-climate-change/accomplishments-and-success-air-pollutiontransportation (accessed on 20 June 2021).

2. Müller, A.; Österlund, H.; Marsalek, J.; Viklander, M. The pollution conveyed by urban runoff: A review of sources. Sci. Total Environ. 2020, 709, 136125. [CrossRef] [PubMed]

3. US EPA. Progress Cleaning the Air and Improving People's Health. USEPA. 8 June 2015. Available online: https://www.epa. gov / clean-air-act-overview/progress-cleaning-air-and-improving-peoples-health (accessed on 20 June 2021).

4. Air Quality-Particle Pollution I CDC. 4 September 2019. Available online: https://www.cdc.gov/air/particulate_matter.html (accessed on 20 June 2021).

5. Air Pollutants. Available online: https://www.iowadnr.gov/environmental-protection/air-quality/air-pollutants (accessed on 20 June 2021).

6. Pirjola, L.; Kulmala, M.; Wilck, M.; Bischoff, A.; Stratmann, F.; Otto, E. Formation of sulphuric acid aerosols and cloud condensation nuclei: An expression for significant nucleation and model comprarison. J. Aerosol Sci. 1999, 30, 1079-1094. [CrossRef]

7. Korhonen, H.; Lehtinen, K.E.; Kulmala, M. Multicomponent aerosol dynamics model UHMA: Model development and validation. Atmos. Chem. Phys. 2004, 4, 757-771. [CrossRef]

8. Pohjola, M.; Pirjola, L.; Kukkonen, J.; Kulmala, M. Modelling of the influence of aerosol processes for the dispersion of vehicular exhaust plumes in street environment. Atmos. Environ. 2003, 37, 339-351. [CrossRef]

9. Lurmann, F.; Wexler, A.; Pandis, S.; Musarra, S.; Kumar, N.; Seinfeld, J. Modelling urban and regional aerosols-II. Application to California's south coast air basin. Atmos. Environ. 1997, 31, 2695-2715. [CrossRef]

10. Jacobson, M.Z. Development and application of a new air pollution modeling system-II. Aerosol module structure and design. Atmos. Environ. 1997, 31, 131-144. [CrossRef]

11. Zhang, Y.; Pun, B.; Vijayaraghavan, K.; Wu, S.; Seigneur, C.; Pandis, S.N.; Jacobson, M.Z.; Nenes, A.; Seinfeld, J.H. Development and application of the model of aerosol dynamics, reaction, ionization, and dissolution (MADRID). J. Geophys. Res. Atmos. 2004, 109. [CrossRef]

12. Holmes, N.S.; Morawska, L. A review of dispersion modelling and its application to the dispersion of particles: An overview of different dispersion models available. Atmos. Environ. 2006, 40, 5902-5928. [CrossRef]

13. Ermak, D.L. An analytical model for air pollutant transport and deposition from a point source. Atmos. Environ. 1977, 11, 231-237. [CrossRef]

14. Nimmatoori, P.; Kumar, A. Development and evaluation of a ground-level area source analytical dispersion model to predict particulate matter concentration for different particle sizes. J. Aerosol Sci. 2013, 66, 139-149. [CrossRef]

15. Snyder, M.G.; Venkatram, A.; Heist, D.K.; Perry, S.G.; Petersen, W.B.; Isakov, V. RLINE: A line source dispersion model for near-surface releases. Atmos. Environ. 2013, 77, 748-756. [CrossRef] 
16. Madiraju, S.V.H.; Kumar, A. Development and Evaluation of SLINE 1.0, a Line Source Dispersion Model for Gaseous Pollutants by Incorporating Wind Shear Near the Ground under Stable and Unstable Atmospheric Conditions. Atmosphere 2021, 12, 618. [CrossRef]

17. Rao, K.S. Analytical Solutions of a Gradient-Transfer Model for Plume Deposition and Sedimentation; National Service Center for Environmental Publications (NSCEP): Boston, MA, USA, 1982.

18. United States Environmental Protection Agency. AERMOD Deposition Algorithms-Science Document (Revised Draft); Research Triangle Park, US EPA: Washington, DC, USA, 2009.

19. Milando, C.W.; Batterman, S.A. Operational evaluation of the RLINE dispersion model for studies of traffic-related air pollutants. Atmos. Environ. 2018, 182, 213-224. [CrossRef] [PubMed]

20. Nimmatoori, P.; Kumar, A. Application and sensitivity analysis of two screening dispersion models (SCREEN3 AND AERSCREEN) for a ground-level area source. Int. J. Environ. Sci. Eng. Res. 2013, 4, 12.

21. United States Environmental Protection Agency. AERSCREEN User's Guide; EPA-454/B-11-001; Research Triangle Park, US EPA: Washington, DC, USA, 2011.

22. Wark, K.; Warner, C.F.; Wayne, D.T. Air Pollution: Its Origin and Control; Addison-Wesley: Boston, MA, USA, 1998.

23. Oracle. Crystal Ball. Available online: https://www.oracle.com/applications/crystalball/ (accessed on 1 June 2021).

24. Modeling and Simulation. Available online: http://home.ubalt.edu/ntsbarsh/Business-stat/simulation/sim.htm (accessed on 20 June 2021).

25. Madiraju, S.V.H.; Kumar, A. Development of a Line Source Dispersion Model for Gaseous Pollutants by Incorporating Wind Shear near the Ground under Stable Atmospheric Conditions. Environ. Sci. Proc. 2021, 4, 8154. [CrossRef]

26. Madiraju, S.V.H.; Kumar, A. Dispersion Modeling of Gaseous Emissions from Mobile Area Sources by Incorporating Wind Shear Near the Ground. In Proceedings of the A\&WMA's 114th Annual Conference \& Exhibition, Online, $14-17$ June 2021.

27. Madiraju, S.V.H.; Kumar, A. An Intercomparison of Performance and Sensitivity of Four Generic Mobile Source Dispersion Models. In Proceedings of the IGSCONG'21, Online, June 2021. 